\title{
Hypertension Induction and Avoidance in the Patients with Neurosurgical Pathologies and Concomitant Cardiovascular Disorders
}

\author{
Behzad Saberi* \\ Medical research, Iran
}

*Corresponding author: Behzad Saberi, Medical research, Esfahan, Iran.

Received Date: June 22, 2019

Published Date: July 01, 2019

\section{Short Communication}

When dealing with patients with neurosurgical pathologies whom have concomitant cardiovascular problems, the important question which the clinician is faced with it is that "Shoud I 'avoid' or 'induce' HTN in this case?". These two opposite hemodynamic goals are of great importance to manage this patients group. Avoiding HTN or low normotensive state is necessary when dealing with AVMs and ruptured aneurysms to avoid rebleeding but it is important to avoid any hypotension induction because it may cause brain hypoperfusion. Avoiding HTN can be done by employing beta-blockers in hypertensive patients, norepinephrine and phenylephrine as vasopressors, dobutamine and epinephrine as inotropes and nomodipine as vasodilator. HTN induction is necessary in some procedures including neurointerventional and neurosurgical ones to keep the CPP in a normal range. Thrombolysis, microcatheters, cerebral stenting, intracranial bypass, angioplasty and carotid clamping are some of these procedures which require HTN induction which can be achieved by employing vasopressors with or without alteration in intravascular volume to increase the patient's blood pressure 20 to 40 percent above the normal range. Diminished cardiovascular reserve conditions such as CAD or CHF with the risk of cardiac decompensation, require such induction to be individualized for these specific conditions. If the measured neural function can be normal during some procedures, HTN induction can be eliminated. In the patients with DCM, stenotic valvular heart disease and HOCM, due to the risk of cardiac decompensation and pulmonary edema, hypervolemia should be avoided during some procedures like in the management of SAH aneurysms. In these patients, fluid therapy should be defined based on the goals and using TEE or PA catheter can be helpful to manage the hemodynamic conditions of these patients during such procedure.

\section{Acknowledgement}

None.

\section{Conflict of Interest}

No conflict of interest.

\section{References}

1. Jain A, Dogra N, Mangal K (2010) To evaluate the heart or not in emergency neurosurgical head-injured patients with ST elevation. Ann Card Anaesth 13: 268-269.

2. Hunt WE, Hess RM (1968) Surgical risk as related to time of intervention in the repair of intracranial aneurysms. J Neurosurg 1: 14-20.

3. Schubert A (2007) Cardiovascular therapy of neurosurgical patients. Best Pract Res Clin Anaesthesiol 21: 483-496.

4. Zou R, Shi W, Tao J, Li H, Lin X, et al. (2017) Neurocardiology: cardiovascular changes and specific brain region infarcts. Biomed Res Int: 5646348.

5. Kerro A, Woods T, Chang JJ (2017) Neurogenic stunned myocardium in subarachnoid hemorrhage. J Crit Care 38: 27-34.

6. Bederson JB, Connolly ES Jr, Batjer HH, Dacey RG, Dion JE, et al. (2009) Guidelines for the management of aneurysmal subarachnoid hemorrhage: a statement for healthcare professionals from a special writing group of the Stroke Council, American Heart Association. Stroke 40: 994-1025. 